\title{
New Zealand's Energy Future: A Review of A Sustainable Energy Future for New Zealand by 2050 and Future Currents
}

\author{
Ralph Chapman and Ken Piddington
}

\section{Introduction}

Not for a few decades has there been a greater level of concern about New Zealand's longer-term energy future, and the interplay between energy issues and climate change issues. In particular, energy issues continue to vex many New Zealanders, not least those facing the prospect of new electricity transmission pylons south of Auckland, energy users worried about supply shortages over the next winter, and vehicle drivers facing another oil price increase as crude oil in world markets hovers around US\$70 per barrel. At the same time, concerns about climate change are intensifying, with some arguing that New Zealand government policy advisers and ministers have failed to grasp the magnitude of this issue. Currently, advisers are exploring new climate change policy instruments, following the government's decision to drop the carbon tax which had been scheduled for introduction in April 2007.

Issues of energy insecurity, peak oil and climate change were all identified in the government's Sustainable Energy document of October 2004; what is surprising, even taking into account the discontinuity of the 2005 election, is the lack of progress on them since 2004. A positive sign, however, is the reference in the November 2005 Speech from the Throne, where it was stated that 'the Government would in this term explore a wide range of potential energy scenarios, in order to develop a National Energy Strategy'.

Leaving aside some lower-profile research contributions (e.g. Sims et al., 2005; Ministry of Economic Development, 2003; Chapman et al., 2003), two key recent documents have begun such an exploration, sketching out paths to a range of energy futures. They are the New Zealand Business Council for Sustainable Development's document, A Sustainable Energy Future for New Zealand by 2050: a business view (September
2005) and the Parliamentary Commissioner for the Environment's Future Currents: electricity scenarios for New Zealand 2005-2050 (July 2005). We review the approaches taken and conclusions reached in the two documents. In doing so, we emphasise the strong connections between energy and climate change policy for New Zealand. We give more space to the Business Council's document simply because, covering energy as a whole, it takes a rather wider view than the Parliamentary Commissioner's document, which focuses only on electricity.

\section{What does the Business Council document do?}

The Business Council (BCSD) document scans the wider energy sector, and in so doing provides a wellresearched account of perspectives of interest to the business sector. It starts from the hypothesis of transition - meaning that in 2050 New Zealand's energy sector will have a much more sustainable profile than we see in that sector today. It also builds in a timeframe for the decisions which have to be made in order to achieve 'energy sustainability' by that date.

The BCSD document aims to raise awareness within the business sector of how the economy's future demands for energy could potentially be met in a more environmentally sustainable way, if certain policies are adopted. The analysis is cast at a headline level in terms of achieving energysustainability (which need not imply environmental sustainability), but the text does in fact put considerable weight on environmental goals.

The BCSD document uses a set of four scenarios to explore possible energy future paths and reach certain outcomes by 2050 . It is less clear on the process that might be followed in order to reach the outcomes, although in its final paragraph ('The Challenges Ahead') 
it does assign a leadership role to government in ensuring that we keep our energy options open'.

The scenarios are focused around two main dimensions: GDP growth and energy demand growth. By focusing on these two dimensions, greater and lesser degrees of decoupling (of economic growth from energy demand) are explored. Decoupling of economic growth from environmental impact, and issues of energy security, are also explored (e.g. reduced environmental impact occurs in those future states where low energy demand is projected).

Although the two chosen dimensions of focus (GDP and energy demand) are not the only possible two dimensions to choose as the basis of energy scenarios, they are undoubtedly important to New Zealand business and to others. Other dimensions of importance both to New Zealand business and to the wider community, but only lightly sketched are environmental sustainability, social/behavioural change and 'energy services' (rather than energy demand per se).

\section{Strong points of the BCSD document}

The BCSD report is valuable in a number of ways for any dialogue about future energy paths.

First, the scenario approach helps the report's audience to visualise a number of future paths which the economy and society could take, and underlines the key point that strategic choices need to be made by both government and the business sector.

Second, the report recognises the key issues of both 'peak oil' and climate change. However, a view that 'global oil production will peak sometime over the next 50 years' is too relaxed a view of this (Hirsch et al., 2005), and the document also radically underestimates the importance of early moves to decarbonise our energy system (see below).

Third, the BCSD report recognises the importance of maintaining system resilience and adaptability by not closing options through poor decisions (i.e. providing 'optionality').

Fourth, it acknowledges that energy infrastructure decisions made now have ramifications for many years ahead. As the report states: 'We made [at various points in our history] large infrastructural decisions that set the course of our energy use for years to come' (p.5). A corollary is that 'Infrastructure investment risks are high and mistakes have long-term costs' (p.5). This point is vital: the effective lifetime of our urban form, for example, is more than 100 years, exceeding even the lifetime of our hydro power stations. In economic terms, there is major 'path dependence' in urban form and other infrastructure decisions, which means that we need to consider timeframes of at least 50 years when investing in energy use or production infrastructure. The likelihood that peak oil and climate change will have fundamentally altered the energy picture by then is very high.

Lastly, many of the BCSD's recommendations make sense; for example, that 'the government needs to understand what drives the acceptability and uptake of energy and usage options in New Zealand' (p.19). This may sound obvious, but the empirical work has often simply not been done to generate an adequate picture of uptake and behaviour.

\section{Gaps in the BCSD approach}

\section{Environmental sustainability}

There is some welcome attention given to environmental sustainability (see 'Sustainability criteria assessment' for each scenario, pp.10-11), but the report in our view radically underestimates the importance of climate change to New Zealand's energy future. Climate change is factored in, but not adequately. For example, even rough indications of future $\mathrm{CO} 2$ emission paths are not provided. Undoubtedly, careful modelling of $\mathrm{CO} 2$ emissions would have been complex, but indicative assessments would have been valuable, given the importance of being able to assess scenarios in terms of climate change policy contribution and policy risk.

The scenarios do acknowledge climate risks, but underestimate the risk of New Zealand facing tight constraints on energy choices due to climate change developments. For example, it is stated that 'New Zealand may become constrained by the way we limit or alter our use of fossil fuels to mitigate potential climate change impacts' (p.3, emphasis added). New Zealand is already constrained by choices of fuels in the past (e.g. use of Maui gas) and will very likely be heavily constrained by climate change requirements in the future. There is a substantial likelihood of New Zealand 
having to make deep reductions in fossil fuel use within a decade, if climate change impacts accelerate or projections become more alarming (e.g. Hansen, 2005), unless we can find other ways to substantially cut our greenhouse gas emissions.

\section{Social/behavioural change}

The BCSD report does not ignore the need for behavioural change ('we will require behavioural change', p.18), but it underplays it, at least in terms of headline presentation, in favour of a stress on technology (especially carbon capture and storage, or CCS) and efficiency.

There is some implicit attention to changes in social and behavioural patterns (e.g. under 'How we live', p.12; in respect of both Conservation and Transformation scenarios, pp.10-11, brief reference to affordability; and p.19) but this tends to be overwhelmed by the focus on technological change. This is captured in the statement that 'We can have high growth and environmental standards only if technology developments are realised' (p.14). This underplays the importance of behaviour (and underlying attitudinal) change.

Similarly, the report's approach does make some connection between social outcomes and energy demand (e.g. 'demand will be an outcome of the type of society we want to build' (p.8)), but this is not elaborated significantly. Moreover, the various dimensions of social and behavioural change are not explored in depth. It would have been helpful to see a discussion of the relative scope for technological as against social/behavioural change.

The report does acknowledge that this is a 'gap': it states towards the end that 'The focus of the scenario analysis has been largely technical and economic' (p.16). However, it then draws a conclusion which is debatable; that those scenarios which involve more rapid change from 'business as usual' (i.e. the Transformation and Conservation scenarios) suppose 'changes in our society which result in a general acceptance of more direction about the way we use energy' (emphasis added). This remark might be interpreted as doubtful about the acceptability of 'direction'. However, substantial behavioural change might follow from a judicious combination of education, information and application of (reasonable) economic incentives.

\section{Energy services}

The report is light on distinguishing the demand for energy services from energy, yet this is an important distinction if demand is to be fully analysed. There is a reference (p.10) under the Transformation scenario where it is stated that 'change has been assisted by a radical focus on the way New Zealand's social and transport needs are met', but this is not elaborated. Moreover, there is some detailing of transport energy demand (p.12), but little discussion of adaptation (or otherwise) of transport services.

Rather, the approach taken in the report is essentially to distinguish a high rate of AEEI (autonomous energy efficiency improvement) in two scenarios Transformation and Conservation - from a low rate in the two other scenarios - Growth and Shielded. The two AEEI rates assumed are $1.5 \%$ and $0.75 \%$ respectively (p.8). While these rates are not implausible, the approach is a 'black box' one - it is not evident what evolution in energy service demands lie behind these numbers. For this reason, the projections of energy demand in 2050, especially the higher ('business as usual'-type) demand projections, should be seen as indicative only.

\section{Trade-off emphasis}

A feature of the discussion on p.18 is the emphasis on trade-offs ('For a sustainable energy future we face trade-offs between affordability, security of supply and environmental protection'). This formulation is repeated in the conclusion (p.20). This has some immediate appeal - some hard choices will always be necessary - but this particular trade-off does not necessarily stand up. No compelling substantiation of this trade-off is offered.

It can, on the contrary, be argued that in order to maintain development in the longer term that can be 'afforded' in a broad sense, both environmental protection and security of supply are vital. Without investments in technology and behaviour change that are socially and environmentally responsible, the likelihood of ongoing sustainable development is severely reduced. This requires a range of actions going beyond mere 'broadening' (p.18) of renewables: a dramatic uptake of available and new renewables is needed, along with behavioural change, on a timescale 
that reflects the urgency of the climate change issue and the need also to address peak oil.

In the context of maintaining 'optionality', it should be noted that conventional solutions such as lumpy investment in the national grid south of Auckland or in the 'top of the South' may reduce optionality, as well as being environmentally undesirable and possibly less affordable than small-scale distributed generation. Lumpy national grid investment may crowd out the development of a multi-directional grid connecting smaller-scale generating units. Moreover, the challenges facing grid-constrained regions (and rural regions facing disconnection post-2013) may well create opportunities for new partnerships and institutional arrangements. An example might be a public/private partnership in a region such as the East Coast, investing in local resources and using a new financial structure to achieve a broad set of local objectives.

\section{Assumptions in the BCSD report}

A key underlying assumption made in the BCSD analysis is that economic growth is fundamental and is necessary for sustainability:

Growth is a fundamental requirement for economic and social development. (p.1)

Part of this challenge [to shift to more sustainable energy] will be to ensure that we have the economic growth necessary to afford the changes required. In other words, a sustainable energy future will come from growth that in turn is dependent on adequate supplies of affordable energy. (p.3)

This assumption has some superficial basis in the association between more rapid economic growth and faster turnover of capital and take-up of energy efficiency. But the connection is overly simplified; the 'wrong' sort of growth (e.g. growth involving major urban expansion or higher investment in energy-intensive sectors) may make the required shift harder. Moreover, it would be possible to achieve a combination of somewhat slower economic growth and greater environmental sustainability or, more positively, a modest but 'sufficient' rate of economic development associated with enhanced sustainability (Daly, 2005). There is good evidence that this mix is something which New Zealanders would support (see Annex). Literature on the Environmental
Kuznets Curve also shows that there is a variety of future states of economic development and environmental sustainability that can be attained by developed economies, depending on the mix of policies and approaches adopted.

A second important assumption (or rather, set of assumptions) relates to new technology development. For example, the assumption that CCS (carbon capture and storage) could move to commercial viability by 2025 (Growth scenario) seems optimistic. As noted in the document, 'Proven CCS technology is therefore critical [to meeting climate change obligations].' With CCS being critical to the Growth scenario in this sense, that scenario becomes particularly risky. To give due credit, the report does note on p. 15 that all the scenarios (except Conservation) rely on CCS, 'with Growth and Shielded carrying the highest risk should CCS development be either delayed or too costly'. The assumption of increased CCS uptake from 2021 is 'in line with the earliest world view' of demonstration, take-up and availability. The extent of reliance on this risky assumption could perhaps have been given more prominence.

Conversely, a (third) assumption of technological breakthroughs in renewables in the late 2020s is probably too pessimistic, as may be the assumption that smart grid technology would not be available before 2025 (p.15). For photovoltaic, wind and wave energy, the document probably underestimates the impact that technological advance will have on investment decisions across both the public and private sectors, and at both the corporate and individual/community levels. In respect of the grid, there are some signs that innovative solutions are closer than 20 years away. ${ }^{1}$ And Chinese investment plans for new automobile technology suggest that fuel cell vehicles may be available well before 2025 and are likely to be 'widely available' well before 2050 (cf. Figure 8, p.6).

A questionable fourth assumption is that, within the Growth scenario, New Zealand would be able to meet its climate change obligations. The assumption is stated as: 'New Zealand meets its climate change obligations

At the CAE workshop on Distributed Generation in June 2005, a British expert indicated that it was not so much a question of new technological breakthroughs being required to accommodate small, intermittent generators close to the point of use, but rather of a need for new software (at least in the UK) 
through relatively benign environmental pricing instruments that provide assistance to renewable energies' (p.10). Given that energy prices remain low in this scenario, and that renewables stagnate between 2010 and 2020, this outcome seems implausible.

Conversely, a fifth and major assumption relates to the scope for carbon emission mitigation in the absence of new technologies. The assumption that New Zealand's increased carbon emissions 'will not be mitigated until new technologies (e.g. CCS) or alternative fuels (e.g. transport biofuels) become available' (p.16) is not defensible. It downplays the potential for considerable further mitigation through exploitation of other renewables, and behaviour change/energy efficiency.

Lastly, various other assumptions in the report can be debated. For example, it was not realistic in mid-2005 to assume (p.7) that petrol and diesel will be available at $45-55$ cents a litre (wholesale, presumably) until somewhere between 2025 and 2050 .

\section{Conclusion on the BCSD report}

Despite some limitations, the BCSD report is a significant contribution to an enlightened dialogue on energy futures. The emphases on sustainability and on keeping options open in making a transition over the period to 2050 represent real strengths in the document. Some of the assumptions in the document (such as the forces underlying the projected rates of growth in energy demand) can be debated. Nonetheless, this document does provide a useful framework for this dialogue process. It also helps to underline the fact that there is a range of views on the speed of technological and behavioural change, so any future dialogue should draw on a range of experts familiar with the factors which can influence such change in various ways.

Moreover, the report's conclusion that there is a role for government in encouraging choices that are sustainable is worth underlining. The report should have gone further in creating a sense of urgency about the need for environmentally sustainable investments, particularly renewables and behaviour change in areas such as sustainable transport, in the light of the converging concerns of peak oil and climate change. Nevertheless, the BCSD report is likely to have a valuable impact in raising awareness within the business sector of how the economy's future demands for energy could potentially be met in a more environmentally sustainable way, if forward-looking policies are adopted. To that end, it usefully complements other recent publications, namely the government's Sustainable Energy framework document and Future Currents, from the Parliamentary Commissioner for the Environment (PCE).

\section{What does the PCE document do?}

Like the BCSD document, the PCE analysis, Future Currents: Electricity Scenarios for New Zealand 20052050 , uses scenarios as a means to consider future energy paths. Its focus, however, is on electricity rather than the energy system as a whole. The PCE's motivation includes a sense that there has been a lack of futures thinking and strategic planning for electricity and energy issues at an official level in New Zealand since the 1980s. In fact, the PCE report, focusing as it does on environmental implications of trends and changes in the electricity system, is the first of its kind.

The PCE report spells out two distinct scenarios from now to 2050 - Fuelling the Future and Sparking New Designs. They highlight 'how different our futures could be, depending on the decisions we make' (p.3). The former relies on major infrastructure investment, while the latter emphasises smart design to provide energy services in efficient and innovative ways. Decision making also tends to be more conservative in Fuelling the Future, stressing shorter-term goals, the supply side and the goal of low-cost electricity, while Sparking New Designs emphasises longer-term goals, energy efficiency as well as supply, and a focus on energy services rather than low-cost electricity.

\section{Strong points}

The PCE report is accessible and engaging; it makes an innovative effort to bring critical future energy path issues to a wider audience. Its main method for doing this is to explore two scenarios using the device of perspectives from two fictional characters, Shane ('down on the farm') and Robyn ('city life'), who personalise the scenarios. This makes the PCE report highly readable. At the same time, the PCE report, like the BCSD document, is clearly based on a large body of work, including quantitative modelling, which underpin the scenarios and ensure their internal consistency. 


\section{The PCE approach}

Although it is highly innovative and credible (indeed, the Commissioner says in his preface that 'Our scenarios are conservative'), the PCE report is arguably too optimistic in aspects of its Sparking New Designs scenario. For example, it projects zero emissions (CO2) from the electricity sector by 2050 , on the basis that all power generation is by then renewable. Underlying assumptions include more hydro (e.g. $70 \mathrm{MW}$ in Marlborough) and geothermal (475 MW in the Waikato), as well as more wind and much more solar photovoltaic (1200 MW across New Zealand), and markedly improved energy efficiency. The level of photovoltaic penetration is highly dependent in turn on the assumption of 'very large' cost reductions (p.24).

However, within the domain of scenario building, to say that the Sparking New Designs scenario is too optimistic is arguably not a valid criticism. After all, it is important to choose a range of scenarios that bound the domain of what is reasonably able to be envisaged without having to suspend disbelief. If New Zealand were lucky in terms of imported technology breakthroughs in areas such as photovoltaics, then an outcome of zero carbon emissions from electricity could be attainable. It should be noted that such an outcome could be expected to be accompanied by markedly less pressure on energy prices generally, since worldwide, photovoltaics could be expected to be displacing fossil fuel use.

Sparking New Designs is best seen as a credible view of the future at one end of the spectrum, the purpose of which is to facilitate the process of taking the steps to get from here to there - i.e. to aid the 'backcasting' process. Fuelling the Future, the alternative scenario, is in this sense a characterisation of the sort of future we may face if more enlightened policies are not taken up. It is not a disastrous future, but it is one in which little progress has been made to deal with the twin issues of how to improve electricity efficiency and how to reduce New Zealand's carbon emissions. In this sense it is not a sustainable future.

One of the big imponderables with the electricity sector is pinning down future demand. For example, it is arguable that in the process of decarbonising (or reducing the fossil fuel intensity of) our transport system, we may end up using more electricity. One technology which could hasten this outcome is recharging electric vehicles overnight. While 'plug-in' technology is not currently economic, it could well become so quite soon (Public Power Weekly, 2006). In New Zealand, another trend of this sort is the move towards heat pumps: while these are markedly more energy-efficient and more climate-friendly than alternatives such as unflued gas heaters or old-fashioned electric resistance heaters, their rapid rise in popularity may mean an increase in electricity load overall.

\section{Overall conclusions}

The two documents reviewed here are quite different, and illustrate the diversity of thinking on New Zealand's energy future. The BCSD document is targeted at electricity sector and policy professionals who are used to the arcane methodology of energy projections, and can be expected to have a fairly well developed, technically-based view of plausible future paths for $\mathrm{New}$ Zealand's energy system. By contrast, the PCE report, although it deals with a narrower slice of the energy sector, namely electricity, is targeted more broadly, at the informed general reader together with policy professionals. It is a more accessible, user-friendly document, less technical than the Business Council report, but still robust.

Both documents are useful and contain a solid body of argument. Our main criticism is of the Business Council report, which in our view gives too little weight to the climate change issue in its assessment, and underplays the significance of peak oil. The full impact of the probable 'convergence' described above, with climate change and peak oil together exerting a powerful influence on future policy development, is thus obscured. As pointed out in Policy Quarterly No. 2 (Piddington, 2005), it is less important to forecast the exact timing of the peak oil phenomenon than to embark on a transitional strategy, within a framework of risk management. There is now a sufficient body of evidence for us to conclude that climate change policy instruments should be included as an essential part of such a strategy.

In this context, we can see both studies as a contribution to multidimensional (and multidisciplinary) analysis of future options. They will help open up a critical dialogue about energy, the economy, the environment and the future of New Zealand society. The first five years of 


\begin{tabular}{|c|c|c|c|c|c|c|c|c|c|}
\hline \multicolumn{10}{|c|}{$\begin{array}{l}\text { PERSONAL IMPORTANCE -- SUMMARY TABLE } \\
\text { Now can you tell me how important the following aspects of New Zealand are to you PERSONALLY } \\
\text { - where }-0 \text { is not important at all and } 10 \text { is very important? Remember you can say any number } \\
\text { between } 0 \text { and } 10-5 \text { is the mid-point on this scale. }\end{array}$} \\
\hline & \multicolumn{3}{|c|}{ All } & \multicolumn{3}{|c|}{ Maori } & \multicolumn{3}{|c|}{ Business } \\
\hline & $\begin{array}{c}0-3 \\
\%\end{array}$ & $\begin{array}{c}4-6 \\
\%\end{array}$ & $\begin{array}{c}7-10 \\
\%\end{array}$ & $\begin{array}{c}0-3 \\
\%\end{array}$ & $\begin{array}{c}4-6 \\
\%\end{array}$ & $\begin{array}{c}7-10 \\
\%\end{array}$ & $\begin{array}{c}0-3 \\
\%\end{array}$ & $\begin{array}{c}4-6 \\
\%\end{array}$ & $\begin{array}{c}7-10 \\
\%\end{array}$ \\
\hline Quality of life & 0 & 7 & 93 & 1 & 11 & 88 & 0 & 7 & 93 \\
\hline Quality of natural environment & 1 & 12 & 87 & 1 & 18 & 80 & 0 & 12 & 87 \\
\hline Quality of education & 3 & 13 & 83 & 5 & 14 & 81 & 4 & 14 & 82 \\
\hline The public health system & 6 & 16 & 78 & 6 & 20 & 74 & 9 & 16 & 75 \\
\hline Employment prospects & 5 & 18 & 76 & 5 & 19 & 75 & 6 & 19 & 74 \\
\hline Level of wages and salaries & 4 & 23 & 72 & 5 & 26 & 69 & 3 & 23 & 74 \\
\hline Race relations & 8 & 24 & 68 & 6 & 22 & 72 & 9 & 26 & 65 \\
\hline Potential to increase personal wealth & 5 & 27 & 68 & 6 & 25 & 69 & 2 & 29 & 69 \\
\hline Level of economic growth & 4 & 28 & 67 & 5 & 32 & 60 & 3 & 22 & 75 \\
\hline Business opportunities & 5 & 29 & 65 & 6 & 32 & 62 & 2 & 22 & 76 \\
\hline Providing a supportive business environment & 6 & 28 & 64 & 6 & 32 & 61 & 3 & 24 & 73 \\
\hline Quality of artistic and cultural heritage & 10 & 35 & 54 & 4 & 22 & 72 & 9 & 39 & 51 \\
\hline
\end{tabular}

Source: UMR Research (2003) for the Growth and Innovation Advisory Board

this century have delivered ample warning that new approaches will be needed, and that it would be false to rely on 'business as usual' and the illusion of continuity.

In a situation of discontinuity, it is certainly encouraging to find that, both in the business sector and among public sector advisers, there are creative minds preparing for the inevitability of change. We can only hope that this cross-fertilisation of ideas proceeds with a sufficient sense of urgency.

\section{References}

Chapman, R., E. Goldberg, G. Salmon and J. Sinner (2003) Sustainable Development and Infrastructure, report for the Ministry of Economic Development, November, http://www.med.govt.nz/irdev/econ_dev/ infrastructure/reports/maarama/index.html
Speech from the Throne (2005), http:// www.beehive.govt.nz/PrintPrintDocument.aspx? DocumentID $=24330$

Daly, H. (2005) 'Economics in a full world', Scientific American, 293(3), http://billtotten.blogspot.com/2005/ 09/economics-in-full-world.html

Hansen, J. (2005) 'It's not too late', International Herald Tribune, 13 December, http://www.iht.com/articles/ 2005/12/13/opinion/edhansen.php

Hirsch, R., R. Bezdek and R. Wendling (2005) Peaking of World Oil Production: impacts, mitigation and risk management, report for the National Energy Technology Laboratory of the US Department of Energy, www.hilltoplancers.org/stories/hirsch0502.pdf Ministry of Economic Development (2003) New 
Zealand Energy Outlook to 2025. Wellington: MED, http://www.med.govt.nz/ers/en_stats/outlook/

New Zealand Business Council for Sustainable Development (2005) A Sustainable Energy Future for New Zealand by 2050: a business view, http:// www.nzbcsd.org.nz/energy2050

Parliamentary Commissioner for the Environment (2005) Future Currents: electricity scenarios for New Zealand 2000-2050, http://www.pce.govt.nz/reports/ allreports/1_877274_55_0.shtml

Piddington, K. (2005) 'Preparing for "peak oil" - a preliminary agenda', Policy Quarterly, 1(2), pp.25-7, http://www.vuw.ac.nz/ips/publicationspolicy\%20 quarterly\%20issue $\% 202 \% 202005$.pdf

Public Power Weekly (2006) 'Austin, utilities launch campaign for plug-in hybrid vehicles', Public Power Weekly, 30 January, http://www.appanet.org/special/ index.cfm?ItemNumber $=15927$

Sims, R., S. Berndt and M. Ward (2005) Options for Future Energy Research, Development and Demonstration Investment in New Zealand, project report for the Foundation for Research, Science and Technology, Massey University Centre for Energy Research, 8 July

UMR Research (2003) Quantitative Research: summary report including Maori and business, report commissioned by the Growth and Innovation Advisory Board, December, http://www.giab.govt.nz/ uploadedfiles/Documents/Reports/FinalSummtRpt1.pdf

Associate Professor Ralph Chapman is Director of the Graduate Programme in Environmental Studies, Victoria University of Wellington; Ken Piddington is Senior Associate and Adviser on Environmental Policy, Institute of Policy Studies, also at VUW. 